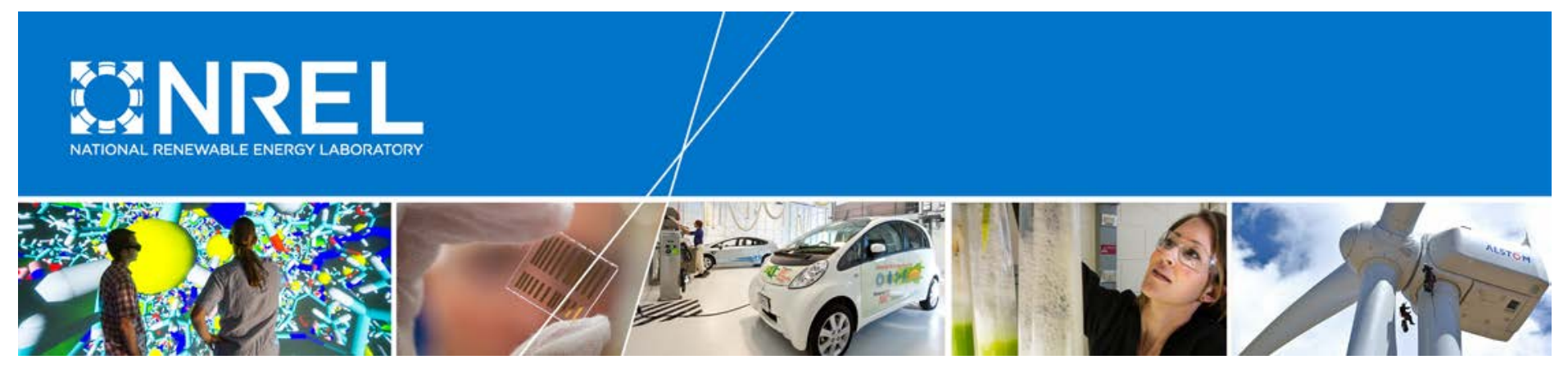

\title{
WEC-SIM Phase 1 Validation Testing - Numerical Modeling of Experiments
}

\section{Preprint}

Kelley Ruehl and Carlos Michelen

Sandia National Laboratories

Bret Bosma

Oregon State University

Yi-Hsiang Yu

National Renewable Energy Laboratory

Presented at the ASME 2016 35th International Conference on Ocean, Offshore and Arctic Engineering (OMAE2016) Busan, South Korea

June 19-24, 2016

NREL is a national laboratory of the U.S. Department of Energy Office of Energy Efficiency \& Renewable Energy Operated by the Alliance for Sustainable Energy, LLC

This report is available at no cost from the National Renewable Energy Laboratory (NREL) at www.nrel.gov/publications.

Conference Paper

NREL/CP-5000-65836

August 2016

Contract No. DE-AC36-08G028308 


\section{NOTICE}

The submitted manuscript has been offered by an employee of the Alliance for Sustainable Energy, LLC (Alliance), a contractor of the US Government under Contract No. DE-AC36-08GO28308. Accordingly, the US Government and Alliance retain a nonexclusive royalty-free license to publish or reproduce the published form of this contribution, or allow others to do so, for US Government purposes.

This report was prepared as an account of work sponsored by an agency of the United States government. Neither the United States government nor any agency thereof, nor any of their employees, makes any warranty, express or implied, or assumes any legal liability or responsibility for the accuracy, completeness, or usefulness of any information, apparatus, product, or process disclosed, or represents that its use would not infringe privately owned rights. Reference herein to any specific commercial product, process, or service by trade name, trademark, manufacturer, or otherwise does not necessarily constitute or imply its endorsement, recommendation, or favoring by the United States government or any agency thereof. The views and opinions of authors expressed herein do not necessarily state or reflect those of the United States government or any agency thereof.

This report is available at no cost from the National Renewable Energy Laboratory (NREL) at www.nrel.gov/publications.

Available electronically at SciTech Connect http:/www.osti.gov/scitech

Available for a processing fee to U.S. Department of Energy and its contractors, in paper, from:

U.S. Department of Energy

Office of Scientific and Technical Information

P.O. Box 62

Oak Ridge, TN 37831-0062

OSTI http://www.osti.gov

Phone: 865.576.8401

Fax: 865.576.5728

Email: reports@osti.gov

Available for sale to the public, in paper, from:

U.S. Department of Commerce

National Technical Information Service

5301 Shawnee Road

Alexandria, VA 22312

NTIS http://www.ntis.gov

Phone: 800.553 .6847 or 703.605 .6000

Fax: 703.605.6900

Email: orders@ntis.gov 


\title{
OMAE2016-54986
}

\section{WEC-SIM PHASE 1 VALIDATION TESTING - NUMERICAL MODELING OF EXPERIMENTS}

\author{
Kelley Ruehl and Carlos Michelen \\ Sandia National Laboratories \\ Albuquerque, New Mexico USA
}

\author{
Bret Bosma \\ Oregon State University \\ Corvallis, Oregon USA
}

\author{
Yi-Hsiang Yu \\ National Renewable Energy Laboratory \\ Golden, Colorado USA
}

\begin{abstract}
The Wave Energy Converter Simulator (WEC-Sim) is an open-source code jointly developed by Sandia National Laboratories and the National Renewable Energy Laboratory. It is used to model wave energy converters subjected to operational and extreme waves. In order for the WEC-Sim code to be beneficial to the wave energy community, code verification and physical model validation is necessary. This paper describes numerical modeling of the wave tank testing for the 1:33-scale experimental testing of the floating oscillating surge wave energy converter. The comparison between WEC-Sim and the Phase 1 experimental data set serves as code validation. This paper is a follow-up to the WEC-Sim paper on experimental testing, and describes the WEC-Sim numerical simulations for the floating oscillating surge wave energy converter.
\end{abstract}

\section{INTRODUCTION}

The Wave Energy Converter Simulator (WEC-Sim) is an open-source code that models the performance of wave energy converters (WECs) in operational and extreme waves. Developed by Sandia National Laboratories and the National Renewable Energy Laboratory, the WEC-Sim code is part of the U.S. Department of Energy Wind and Water Power Technologies Office's initiative to promote and support the emerging wave energy industry. The WEC-Sim code is a timedomain modeling tool developed in Mathworks MATLAB/Simulink using the multibody dynamics solver SimMechanics [1]. WEC-Sim solves the wave energy converter's governing equations of motion using the Cummins time-domain impulse response formulation in 6 degrees of freedom (DOFs) [2].
The WEC-Sim code has undergone verification through code-to-code comparisons [3]; however, validation of the code has been limited to publicly available experimental data sets [4], [5]. Although these data sets provide preliminary code validation, and because the experimental tests were not explicitly designed for code validation, they are limited in their ability to validate the full functionality of the WEC-Sim code. To develop a validation data set for the WEC-Sim code, two phases of testing are planned for dedicated physical model tests of the floating oscillating surge wave energy converter (FOSWEC).

This paper provides a follow-up to the OMAE2016 paper focused on the dedicated WEC-Sim validation experimental wave tank tests performed at the Oregon State University's Directional Wave Basin at Hinsdale Wave Research Laboratory (HWRL) [6]. Phase 1 of experimental testing was focused on the FOSWEC device characterization, and completed in winter 2015. Phase 2 testing will be focused on characterizing the FOSWEC's dynamics and performance, and is scheduled for spring 2016. These experimental tests have been designed explicitly to validate the performance and new features of the WEC-Sim code.

This paper builds on the experimental testing paper, and focuses on the numerical simulations of the Phase 1 experiments. Results of the FOSWEC numerical simulations using the WEC-Sim code will be presented and compared to the experimental data. The following WEC-Sim simulations highlight some of the code features built into the latest release of WEC-Sim (v2.0), including: wave directionality, nonlinear hydrostatics and hydrodynamics, user-defined wave elevation time series, state-space radiation, and compatibility with BEMIO (an open-source code for parsing boundary element method (BEM) coefficients from AQWA, WAMIT, and 
NEMOH) [7]. This paper also includes numerical results using the WEC-Sim code to model the following FOSWEC experimental tests: platform heave, pitch, and surge decay; flap pitch decay. Each of the decay tests were performed for a range of initial displacements and will be used to determine which numerical flags are relevant to model the FOSWEC in WECSim. Comparison of WEC-Sim simulations with and without these additional features will be presented to highlight which numerical flags are relevant for modeling the FOSWEC, as well as demonstrating their functionality.

\section{FOSWEC AND MOTION CONSTRAINT DESIGN}

The FOSWEC was selected for experimental testing because it met the design requirements needed to provide a comprehensive validation data set, as described in the experimental OMAE2016 paper [6], [8]. The FOSWEC design consists of a floating platform with two hinged flaps that rotate in pitch. The FOSWEC platform is free to move in heave, pitch, and surge, but is constrained in roll, sway, and yaw by the motion constraint, and can be configured to iteratively lock the 'free' DOFs.

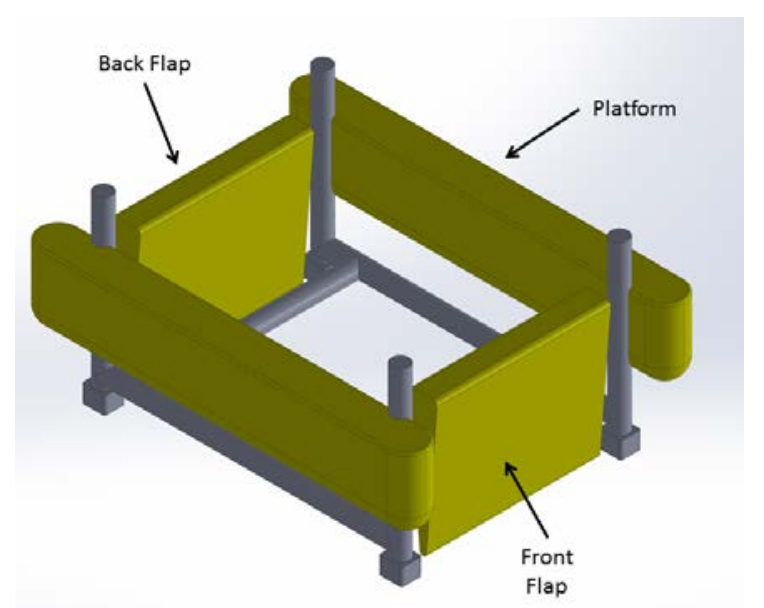

FIGURE 1. THE FOSWEC 1:33-SCALE HYDRODYNAMIC DESIGN USED BY WEC-SIM.

A rendering of the 1:33-scale hydrodynamic design of the FOSWEC used by the BEM and WEC-Sim software to model the device is shown in Figure 1. Figure 3 shows a rendering of the model-scale mechanical design of the FOSWEC, as tested at HSWL. This rendering includes dimensions of the scaled design.

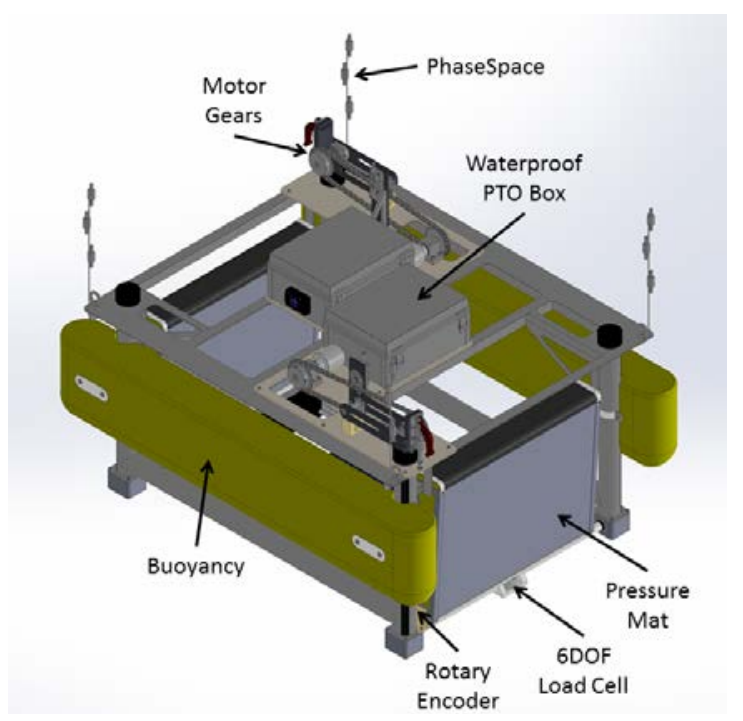

FIGURE 2. THE FOSWEC 1:33-SCALE MECHANICAL DESIGN FOR WAVE BASIN TESTING AT O.H. HINSDALE WAVE RESEARCH LABORATORY.

Although the hydrodynamic design is relevant for numerical modeling, it is also important to have an understanding of the mechanical design of the FOSWEC. The hydrodynamic design is a simplified version of the mechanical design, which includes the design aspects that impact the hydrodynamic performance of the WEC. It also omits extraneous detail, such as anything above the still water line. Even though these geometric features are omitted, they are accounted for in the numerical model through their mass properties. The mechanical design and an overview of the instrumentation are shown in Figure 2. Based on results from swing tests performed at HWRL, the mass properties of the experimental FOSWEC were determined, as described in the Phase 1 experimental paper [6]. The results of this analysis are shown in Table 1. All center of gravity coordinates (cg) are given relative to the origin at the still water line, and moments of inertia are relative to the cg. These are the mass properties that were used in the WEC-Sim numerical model.

TABLE 1. FOSWEC 1:33-SCALE MASS PROPERTIES.

\begin{tabular}{|c|c|c|c|}
\hline & Flap $_{\mathbf{1}}$ & Flap $_{\mathbf{2}}$ & Platform \\
\hline Mass (kg) & 23.14 & 23.19 & 153.8 \\
\hline $\mathbf{X}_{\mathbf{c g}}(\mathbf{m})$ & -0.65 & 0.65 & -0.0009 \\
\hline $\mathbf{Y}_{\mathbf{c g}}(\mathbf{m})$ & 0.0108 & 0.0017 & -0.0044 \\
\hline $\mathbf{Z}_{\mathbf{c g}}(\mathbf{m})$ & -0.29 & -0.29 & -0.063 \\
\hline $\mathbf{I}_{\mathbf{x x}}\left(\mathbf{k g ~ m}^{\mathbf{2}}\right)$ & 1.42 & 1.58 & 37.88 \\
\hline $\mathbf{I}_{\mathbf{v y}}\left(\mathbf{k g ~ m}^{\mathbf{2}}\right)$ & 1.19 & 1.62 & 29.63 \\
\hline $\mathbf{I}_{\mathbf{z z}}\left(\mathbf{k g ~ m}^{\mathbf{2}}\right)$ & 1.99 & 1.25 & 53.61 \\
\hline
\end{tabular}



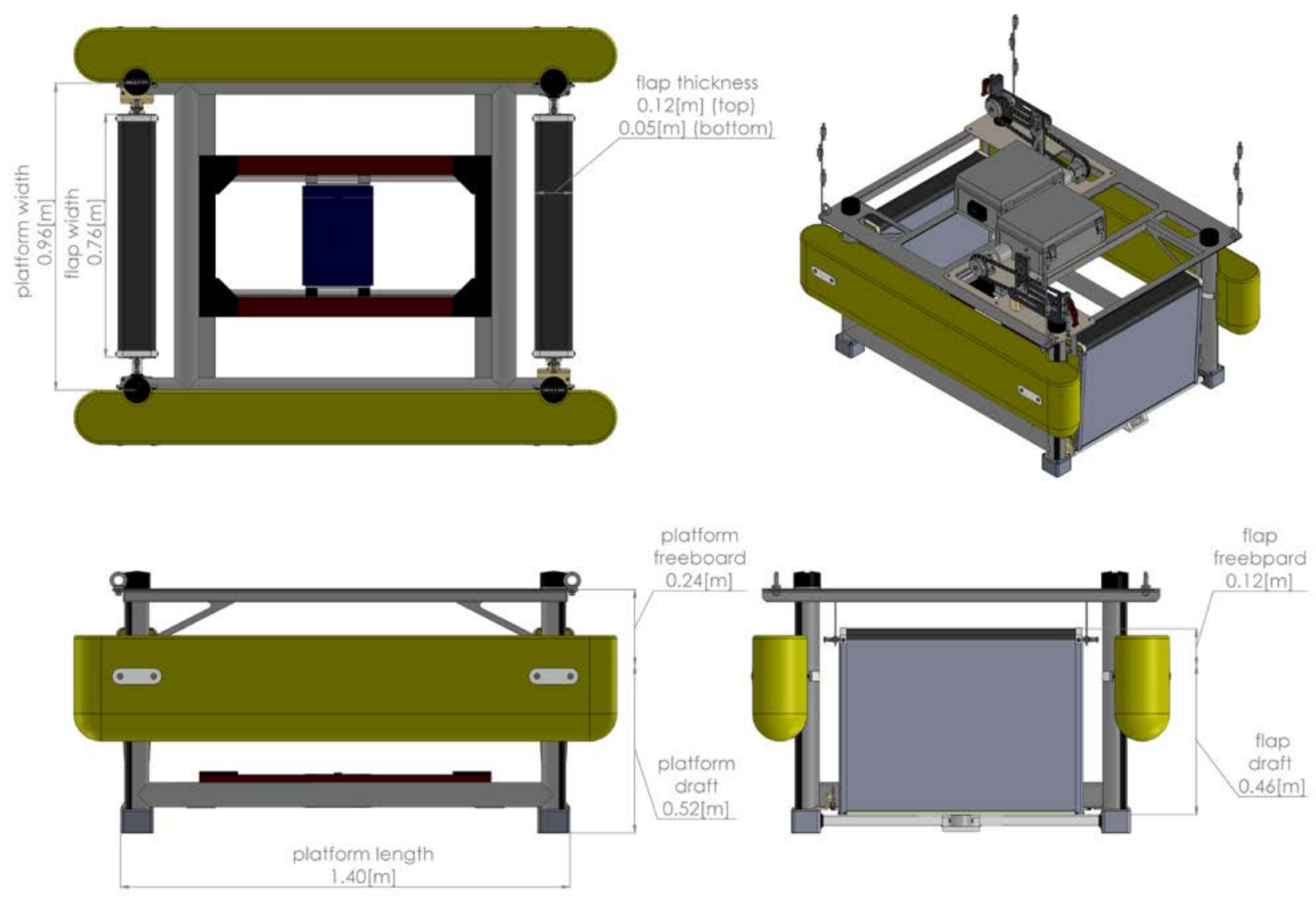

FIGURE 3. FOSWEC 1:33-SCALE DIMENSIONS

In order to characterize the FOSWEC hydrodynamics independent of the influence of mooring forces, a motion constraint was used for the FOSWEC experimental testing. A rendering of the motion constraint is shown in Figure 4. The motion constraint was designed to iteratively lock and unlock the heave, pitch and surge DOFs, and allows the FOSWEC to be characterized in each DOF independently, by isolating motion to heave, pitch or surge motion. Additionally, DOFs can be unlocked to characterize the FOSWEC response in coupled DOFs. When numerically modeling the FOSWEC experiments, the motion constraint mass properties must be included in the simulations since the motion constraint moves with the FOSWEC in each DOF.

For the following description of the motion constraint, refer to Figure 4. Surge motion is constrained by the gray guiderails; these are mounted directly to the FOSWEC platform, and move with the platform in surge. Pitch motion is constrained by the red boxes; these are connected to the surge constraint, so when the FOSWEC pitches, both the red boxes and the gray guiderails move. Heave motion is constrained by the blue cylinders; the upper cylinder moves with the FOSWEC in heave (along with the surge and pitch constraints), while the lower cylinder is mounted directly to the basin floor, and remains stationary.

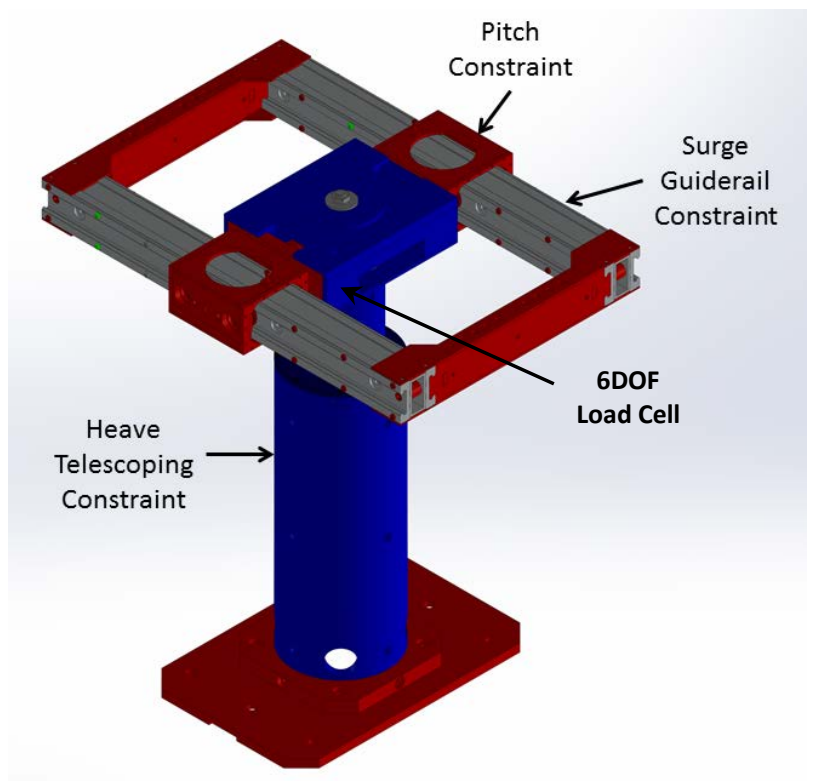

FIGURE 4. MOTION CONSTRAINT MECHANICAL DESIGN, CONSTRAINS FOSWEC MOTION TO HEAVE, PITCH AND SURGE. THE FOSWEC IS MOUNTED TO THE SURGE GUIDERAIL 
The motion constraint mass properties for each DOF are characterized in in Table 2. For numerical modeling purposes, it is critical to include these mass properties in FOSWEC simulations, and to accurately account for how the motion constraint moves with the FOSWEC in each DOF. It is important to note that these mass properties below are for the heave, pitch and surge constraints independently, and do not account for the combined mass properties the FOSWEC would experience when moving in each DOF. For example, for heave motion, the FOSWEC should include heave, pitch and surge motion constraint mass properties.

TABLE 2. MOTION CONSTRAINT MASS PROPERTIES

\begin{tabular}{|c|c|c|c|}
\hline & Heave & Pitch & Surge \\
\hline Mass (kg) & 27.35 & 4.47 & 23.66 \\
\hline $\mathbf{X}_{\mathrm{cg}}(\mathrm{m})$ & 0 & 0 & 0 \\
\hline$Y_{\mathrm{cg}}(\mathrm{m})$ & 0 & 0 & 0 \\
\hline$Z_{\mathrm{cg}}(\mathrm{m})$ & -0.782 & -0.366 & -0.366 \\
\hline$I_{x x}\left(\mathrm{~kg} \mathrm{~m}^{2}\right)$ & 2.2 & 0.29 & 1.44 \\
\hline$I_{\mathrm{yy}}\left(\mathrm{kg} \mathrm{m}^{2}\right)$ & 2.15 & 0.02 & 2.21 \\
\hline$I_{z z}\left(k^{2 g ~ ~^{2}}\right)$ & 0.28 & 0.30 & 3.58 \\
\hline
\end{tabular}

A picture from the FOSWEC experimental testing in the OSU HWRL Directional Wave Basin is shown in Figure 5. For more information about the experimental setup and design of the FOSWEC Phase 1 testing, refer to [6].

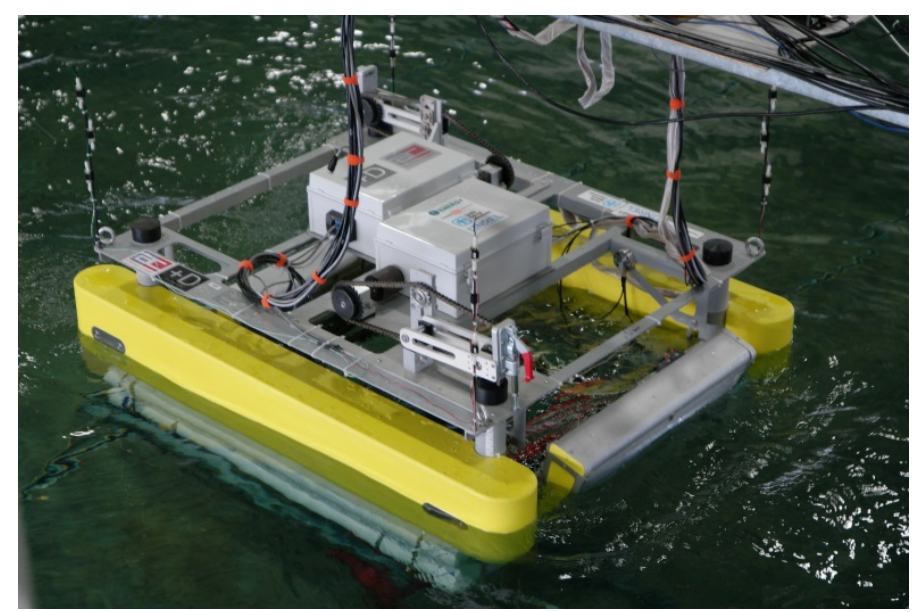

FIGURE 5. EXPERIMENTAL TESTING OF THE 1:33-SCALE FOSWEC (IMAGE COURTESY OF BRET BOSMA)

\section{HYDRODYNAMIC PROPERTIES}

Before running WEC-Sim, a BEM solver must be used to determine the hydrodynamic frequency domain coefficients. WEC-Sim v2.0 is set up to read these parameters from BEMIO parsed output from one of the following BEM codes: AQWA, WAMIT, or NEMOH [9]. The required BEM frequency domain hydrodynamic coefficients include added mass, radiation damping, and Froude-Krylov plus diffraction (excitation) for each body in the model. For the study described in this paper, ANSYS-AQWA was used to generate the frequency domain hydrodynamic coefficients. These coefficients were imported into WEC-Sim by using the BEM parser BEMIO [9]. For reference, the pitch added mass, radiation damping, and excitation magnitude from the front flap BEM solution are presented in Figure 6.
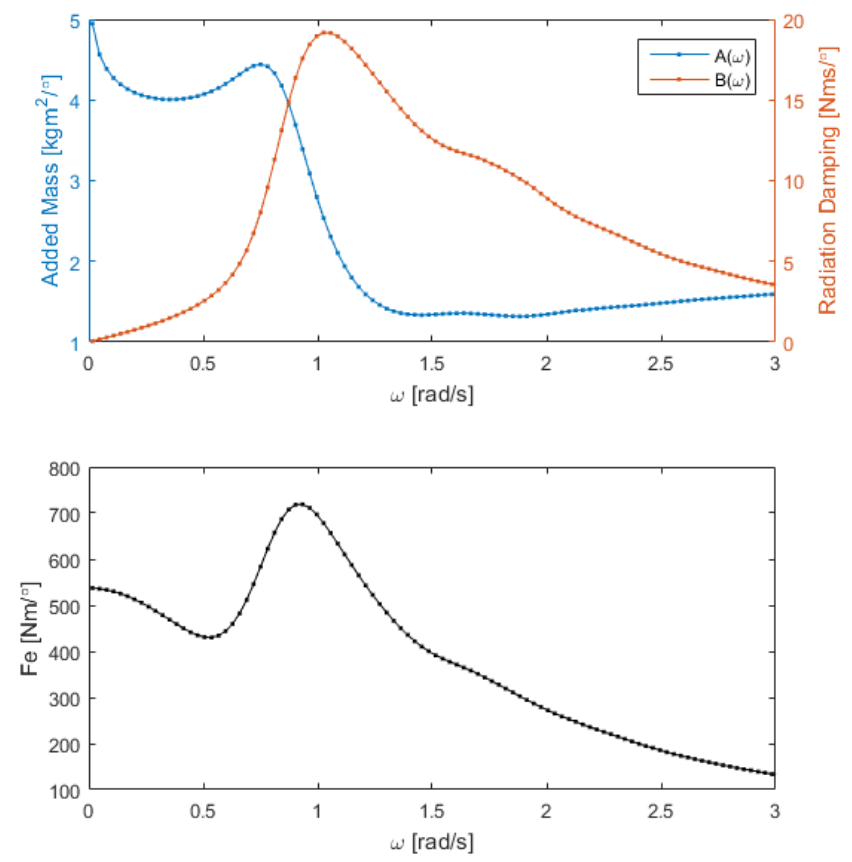

FIGURE 6. FLAP PITCH HYDRODYNAMIC COEFFICIENTS: ADDED MASS, RADIATION DAMPING AND EXCITATION

Once Phase 2 testing is complete, these numerically determined hydrodynamic coefficients will be compared against results from the FOSWEC physical model testing. Forced oscillation tests will be used to determine the radiation and added masses coefficients, and wave excitation tests will be used to determine the excitation coefficients. For reference, the governing WEC equation of motion in regular waves solved by WEC-Sim is defined as the following:

$$
\begin{gathered}
F_{e}(t)=\left(m+A_{j j}(\omega)\right) \ddot{\mathrm{X}}(t)+ \\
\left(B_{j j}(\omega)+C\right) \dot{X}(t)+\rho A C_{D} \dot{X}(t)|X(t)| / 2 \\
+k X(t)+F_{m}(t)+F_{p t o}(t)
\end{gathered}
$$

where $F_{e}(t)$ is the excitation force, $F_{m}(t)$ is the mooring force, $F_{p t o}(t)$ is the PTO force, $m$ is the mass, $j$ is the DOF of interest, $A$ is the added mass, $B$ is the radiation damping, $\omega$ is the angular frequency, $X$ is the displacement, $C$ is the linear damping, $C_{D}$ viscous drag coefficient, and $k$ is the restoring stiffness (or hydrostatic coefficient) of the body.

\section{WEC-SIM NUMERICAL MODEL}

In addition to the physical model testing, the FOSWEC was modeled numerically to compare directly with the experimental data for code validation, as well as to make mechanical design decisions, instrumentation choices, and define power take-off (PTO) requirements. The BEM solver ANSYS-AQWA was used to obtain linear hydrodynamic 
frequency domain coefficients, as described in the previous section. WEC-Sim then uses these coefficients to provide timedomain simulation results of the system. Results from these simulations will be discussed in the following sections.

In order to run WEC-Sim simulations, the FOSWEC model must first be developed using the WEC-Sim Library, consisting of Bodies, Constraints, Joints, Moorings and PTOs, as shown in Figure 7 [10], [11]. A screenshot of the WEC-Sim Simulink model used to simulate the FOSWEC experimental testing is shown in Figure 8. This model consists of a floating platform, two flaps, and a detailed model of the FOSWEC's motion constraint. A benefit of leveraging Mathworks SimMechanics is that WEC-Sim has a graphical user interface that models the FOSWEC's response, as shown in Figure 9.

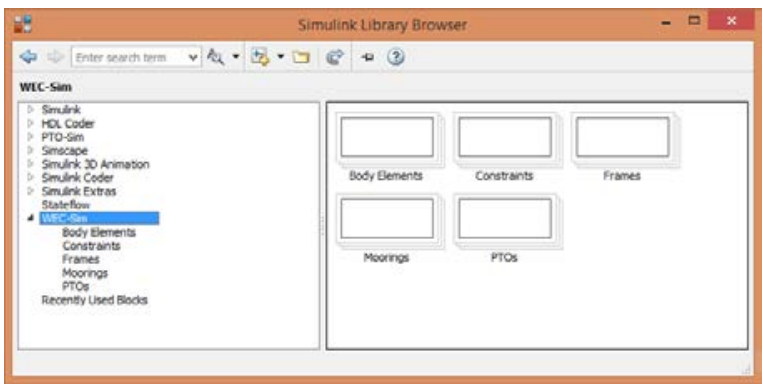

FIGURE 7. WEC-SIM LIBRARY IN SIMULINK

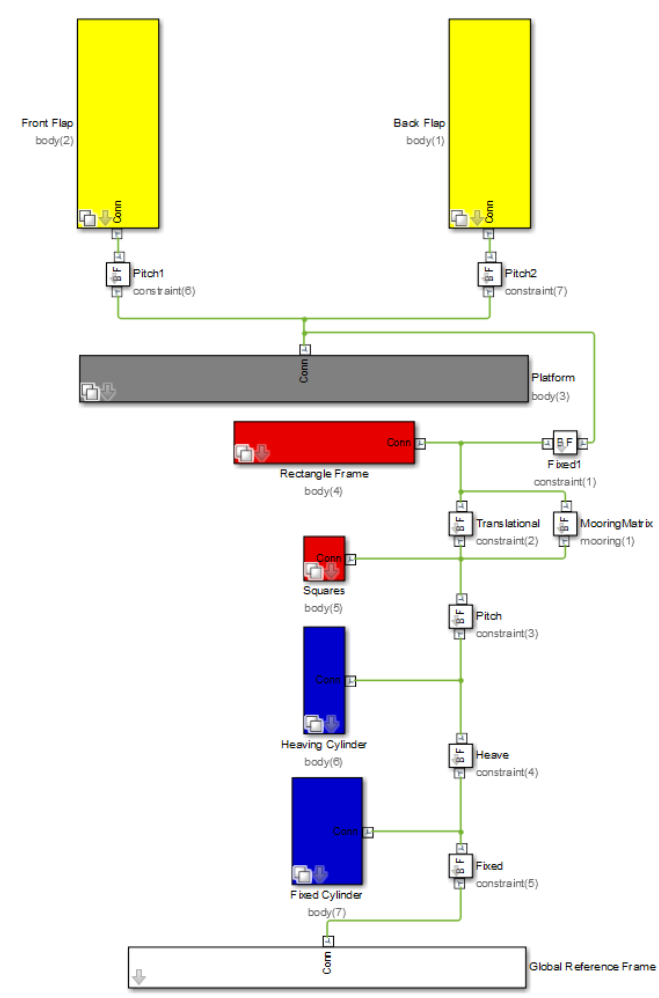

FIGURE 8. MODEL OF THE FOSWEC USING WEC-SIM LIBRARY

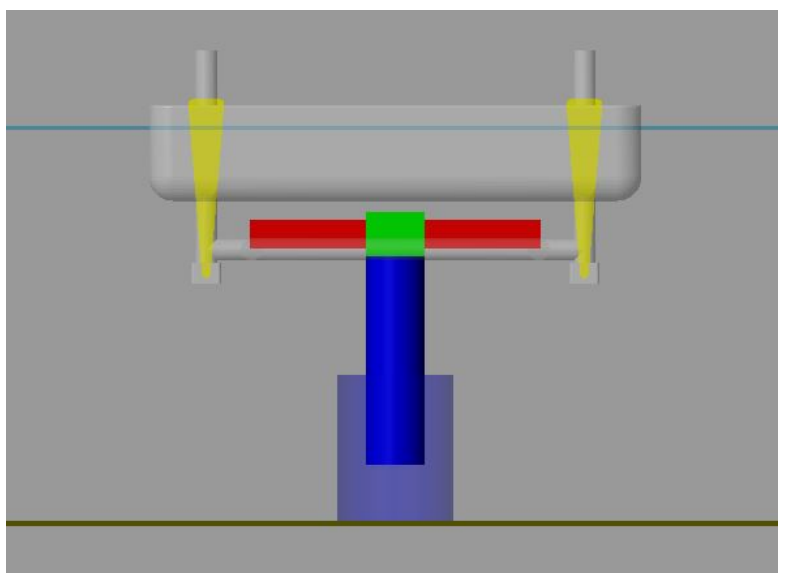

FIGURE 9. FOSWEC MODEL VISUALIZATION IN WEC-SIM

Simulations of the FOSWEC highlight some of the code features included in the latest release of the WEC-Sim code (v2.0), including: wave directionality, nonlinear hydrostatics and hydrodynamics, Morison drag, and compatibility with BEMIO. These features are especially relevant when modeling the FOSWEC, because it is expected that the WEC's response will be highly directionally dependent, have coupling between DOFs and body-to-body interactions, as well as highly nonlinear hydrodynamic response.

\section{SIMULATION RESULTS}

In the following sections, results from numerical simulations of the Phase 1 experiments using WEC-Sim are presented. The WEC-Sim code was used to model the following FOSWEC experimental tests: FOSWEC heave, pitch, and surge decay, and flap pitch decay. The experimental decay tests were performed for a range of initial displacements, each of which was repeated to quantify experimental error. Comparison of these experimental results to the numerical model was then used to determine which numerical flags are relevant to model the FOSWEC dynamics in WEC-Sim. In the following sections, comparison of WEC-Sim simulations to the experimental data with and without these additional features are presented to demonstrate their functionality, as well as to highlight which numerical flags are relevant for modeling the FOSWEC dynamics. For all WEC-Sim simulations, drag coefficients were chosen based on the ones used to model the Langlee inspired NumWEC device [12].

\section{FOSWEC Heave Decay}

In order to characterize the FOSWEC's response in heave, a series of heave decay tests were performed. During these tests, the FOSWEC was raised out of the water with an overhead crane to initial heave displacements of $3,5,7,10$, and $15 \mathrm{~cm}$, and then released. For the heave decay tests, the motion constraint was locked in all DOFs except heave, so the FOSWEC response was isolated to heave motion. The FOSWEC heave decay motion when subject to different initial displacements was then measured with a tape extension position sensor, details of which are provided in [6]. 
In order to compare the numerical flags in the WEC-Sim code, heave decay simulations were run in WEC-Sim with and without the nonlinear drag term $\left(\mathrm{C}_{\mathrm{d}}\right)$, for the same damping value of $450 \mathrm{Ns} / \mathrm{m}$. The results of these simulations are shown in Figure 10. The simulations with a $\mathrm{C}_{\mathrm{d}}$ of 1.28 are dotted, and the simulations with $\mathrm{C}_{\mathrm{d}}$ of zero are dashed. The simulations including the nonlinear drag term differ as a function of the initial displacement, whereas the simulations without a nonlinear drag term collapse around the same solution. This result is expected, because linear responses are independent of displacement; the only way to account for response as a function of displacement is to include nonlinearities, such as drag, into the model.

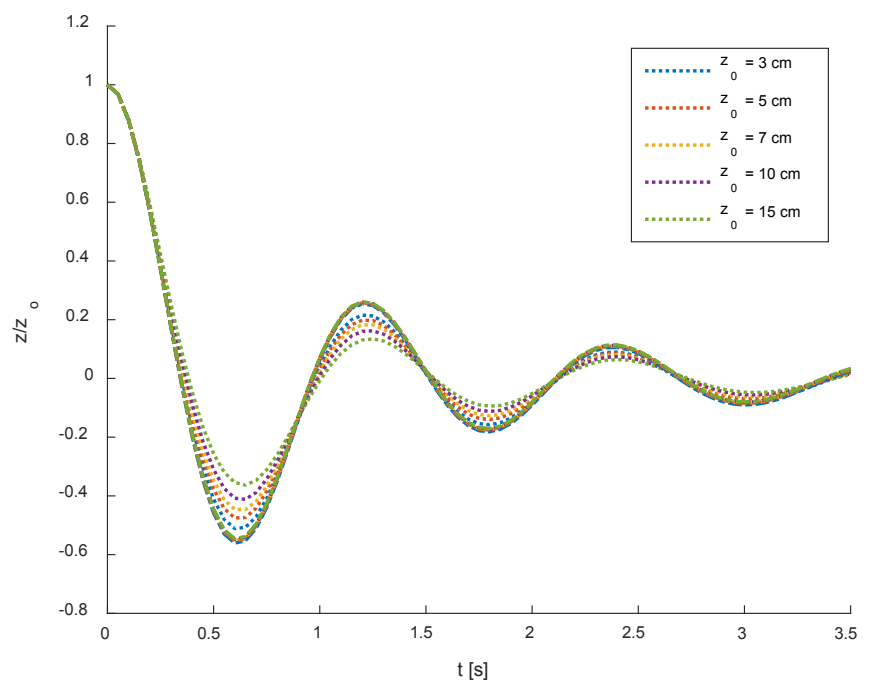

FIGURE 10. NORMALIZED WEC-SIM HEAVE DECAY SIMULATIONS FOR DAMPING OF 450, AND $C_{D}$ OF 1.28 (DOTTED), AND DAMPING OF 450, AND $_{\mathrm{D}}$ OF 0 (DASHED)

The FOSWEC heave decay experiments were then simulated in WEC-Sim, and compared to results from the experimental data. Figure 11 shows the results of the FOSWEC heave decay experiments normalized by the initial displacement (solid lines). The error bars represent the 90\% confidence interval of the experimental data. The dotted lines in Figure 11 are the results of the WEC-Sim heave decay simulations using linear hydrostatics, a linear damping value of $450 \mathrm{Ns} / \mathrm{m}$, and a non-linear drag coefficient of 1.28. The results of the numerical simulations using WEC-Sim have good agreement with the experimental data in terms of decay rate, but the damped natural periods differ. The heave decay experiments have a natural period of $1.56 \mathrm{~s}$, while the WEC-Sim results have a natural period of $1.2 \mathrm{~s}$, yielding a $23 \%$ difference. Additionally, as with the experimental data, the results of the WEC-Sim simulations vary as a function of the initial displacement.

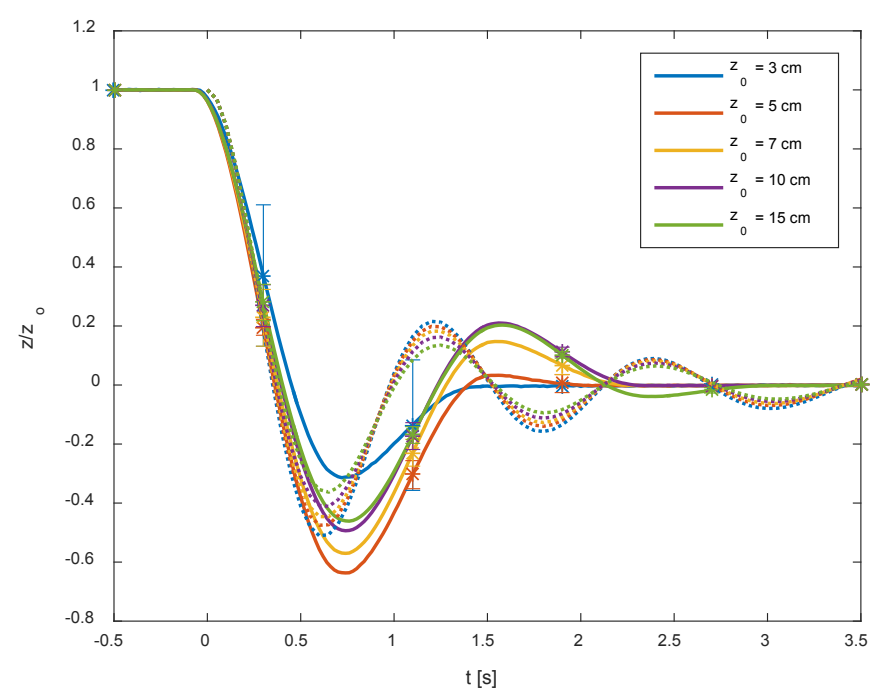

FIGURE 11. NORMALIZED FOSWEC HEAVE DECAY EXPERIMENTAL RESULTS WITH 90\% CONFIDENCE INTERVAL (SOLID), AND WECSIM HEAVE DECAY SIMULATIONS WITH DAMPING OF 450, AND $\mathrm{C}_{\mathrm{D}}$ OF 1.28 (DOTTED)

\section{FOSWEC Pitch Decay}

In order to characterize the FOSWEC's response in pitch, a series of pitch decay tests were performed. This was done by raising one side of the FOSWEC out of the water with an overhead crane to different initial pitch displacements of 5,7 , 10,15 , and $20^{\circ}$, and then releasing it. The motion constraint was locked in all DOFs except pitch, so the FOSWEC response was isolated to pitch motion. The motion of the FOSWEC pitch decay when subject to different initial displacements was then measured by the PhaseSpace motion tracking system, details of which are provided in [6].

Results from the WEC-Sim simulations are first compared to the pitch decay experimental data for the $5^{\circ}$ initial displacement (the median displacement) in Figure 12. The WEC-Sim code was then run with linear damping of 40 $\mathrm{Nms} / \mathrm{rad}, \mathrm{C}_{\mathrm{d}}$ of 8 , and with linear and nonlinear hydrostatics. In Figure 12 , the pitch decay experimental data is shown as a solid line with a damped natural period of 1.64s. Numerical results from the linear hydrostatic WEC-Sim simulation are shown as a dashed line, and have a natural period of $076 \mathrm{~s}$ ( $54 \%$ difference). Results from the nonlinear hydrostatic model are shown as a dotted line, and have a natural period of $1.26 \mathrm{~s}$ ( $30 \%$ difference). Since the nonlinear WEC-Sim results are more representative of the physical experiments, they were used for the remaining pitch decay simulations. For more information about the implementation of nonlinear hydrostatics in WEC-Sim, refer to the WEC-Sim documentation [11], [13]. 


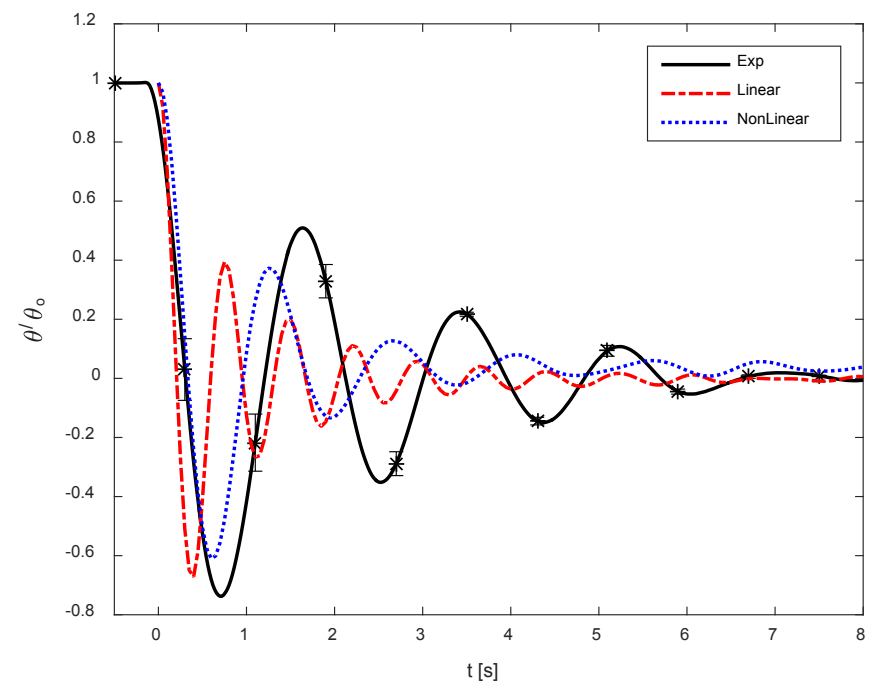

FIGURE 12. NORMALIZED PITCH DECAY FOR $5^{\circ}$ INITIAL DISPLACEMENT, EXPERIMENTAL RESULTS (SOLID), LINEAR WECSIM (DASHED), NONLINEAR WEC-SIM (DOTTED)

The pitch decay experimental results are then compared to the WEC-Sim nonlinear simulations, shown in Figure 13. The experimental data is shown in a solid line with error bars denoting the $90 \%$ confidence interval. Numerical results from the WEC-Sim pitch decay simulations for each initial displacement, run with nonlinear hydrostatics, damping of 40 $\mathrm{Nms} / \mathrm{rad}$, and $\mathrm{C}_{\mathrm{d}}$ of 8 are shown as dotted lines. There is decent agreement between the experimental data and the corresponding WEC-Sim simulations. While the experimental and numerical results exhibit similar natural periods and decay rates, the pitch decay simulations require further investigation.

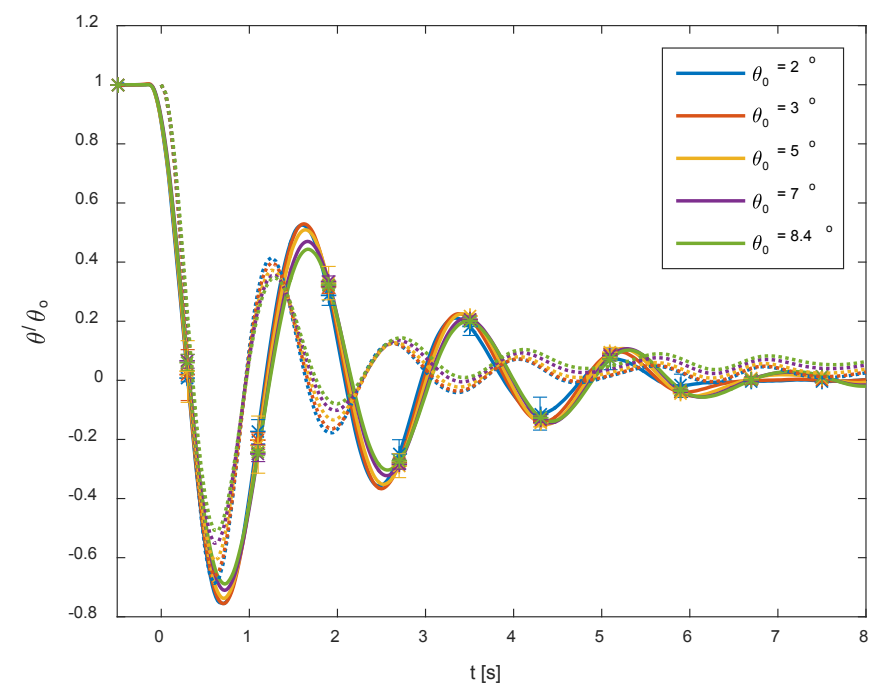

FIGURE 13. NORMALIZED FOSWEC PITCH DECAY EXPERIMENTAL RESULTS WITH 90\% CONFIDENCE INTERVAL (SOLID), AND WECSIM PITCH DECAY SIMULATIONS WITH NONLINEAR HYDROSTATICS, DAMPING OF 40, AND C ${ }_{D}$ OF 8 (DOTTED)

\section{FOSWEC Surge Decay}

In order to characterize the FOSWEC's response in surge, a series of surge decay tests were performed. These experiments were completed by pulling the FOSWEC horizontally with the overhead crane to different initial surge displacements of $7,10,15$ and $20 \mathrm{~cm}$, and then releasing it. The motion constraint was locked in all DOFs except surge, so the FOSWEC response was isolated to surge motion. Since the FOSWEC has a natural restoring force due to hydrostatic stiffness in heave and pitch, no additional stiffness or restoring forces were required. However, for surge motion, there is no hydrostatic restoring force, so bungee cords were used to bring the FOSWEC back to equilibrium. The restoring stiffness of the bungee cords was characterized by a surge static offset test. Results from the surge static offset test are presented as a force versus displacement curve in Figure 14. A linear regression of the force versus displacement curve resulted in a slope, or stiffness, of $962 \mathrm{~N} / \mathrm{m}$, with a correlation coefficient $\left(\mathrm{R}^{2}\right)$ of 0.96 . This stiffness value was then used in the following WECSim simulations.

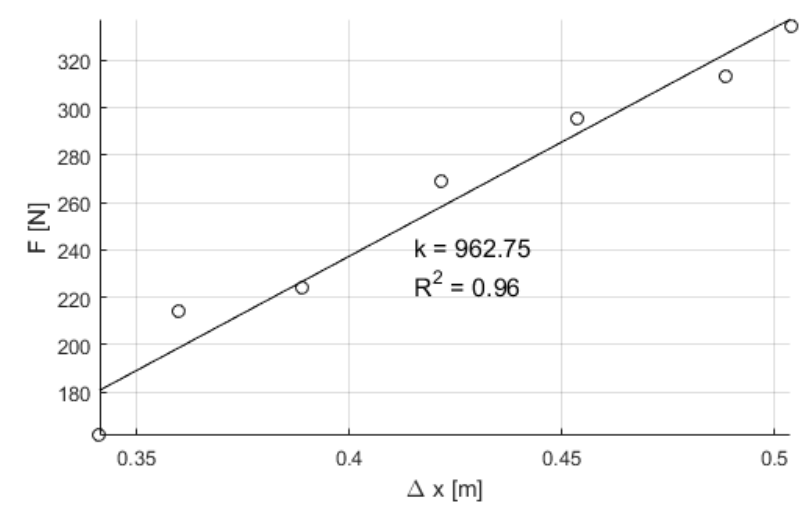

FIGURE 14. FOSWEC SURGE STATIC OFFSET TEST, FORCE VERSUS DISPLACEMENT SLOPE, $\mathrm{K}=962$ WITH $\mathrm{R}^{2}=0.96$

Motion of the FOSWEC surge decay when subject to different initial displacements was then measured with a tape extension position sensor, details of which are provided in [6]. Simulations of the surge decay tests were then run in WEC-Sim using a linear stiffness of $962 \mathrm{~N} / \mathrm{m}$, a linear damping of 770 $\mathrm{Ns} / \mathrm{m}$, and a drag coefficient of 1.28 . Results from the surge decay experimental tests with a $90 \%$ confidence interval, and the WEC-Sim simulations are shown in Figure 15. There is good agreement between the WEC-Sim results and the experimental data in terms of decay rate and settling time. 


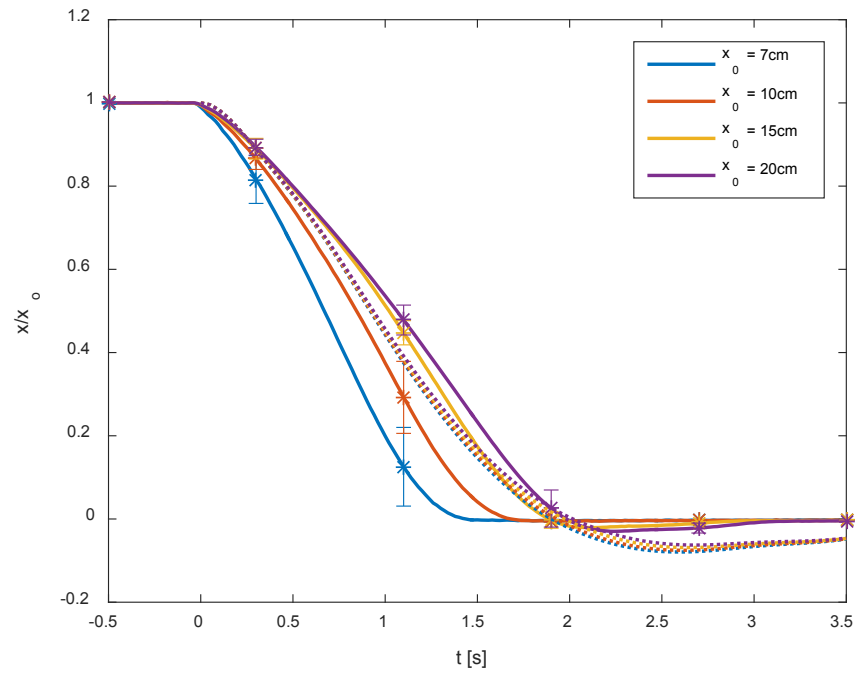

FIGURE 15. NORMALIZED FOSWEC SURGE DECAY EXPERIMENTAL RESULTS WITH 90\% CONFIDENCE INTERVAL (SOLID), AND WECSIM SURGE DECAY SIMULATIONS WITH STIFFNESS OF 962, DAMPING OF 770, AND C ${ }_{\mathrm{D}}$ OF 1.28 (DOTTED)

\section{Flap Pitch Decay}

In order to characterize the flap's response in pitch, a series of flap decay tests were performed. These were done by using the overhead crane to pull the flap to initial pitch displacements of $5,7,10,15$, and $20^{\circ}$, and then releasing it. The motion constraint was locked in all DOFs, so the FOSWEC response was isolated to flap pitch. The FOSWEC flap's decay motion when subject to different initial angular displacements was then measured by a rotary encoder mounted on the flap's shaft, details of which are provided in [6].

As shown in Figure 16, the WEC-Sim simulations are first compared to the flap pitch decay experimental data for the $10^{\circ}$ initial displacement (the median displacement). The WEC-Sim code was then run with a linear damping of $0 \mathrm{Nms} / \mathrm{rad}$, and $\mathrm{C}_{\mathrm{d}}$ of 8, with linear and nonlinear hydrostatics. In Figure 16, the flap pitch decay experimental data is shown as a solid line, and has a damped natural period of 3.88s. The linear hydrostatic WEC-Sim simulation is shown as a dashed line, and has a natural period of $1.55 \mathrm{~s}(60 \%$ difference $)$. The nonlinear hydrostatic simulation is shown as a dotted line, and has a natural period of $3.78 \mathrm{~s}$ ( $3 \%$ difference). Since the nonlinear WEC-Sim results are more representative of the physical experiments, they were used for the remaining flap pitch decay simulations. For more information about the implementation of nonlinear hydrostatics in WEC-Sim, refer to the WEC-Sim documentation [11], [14].

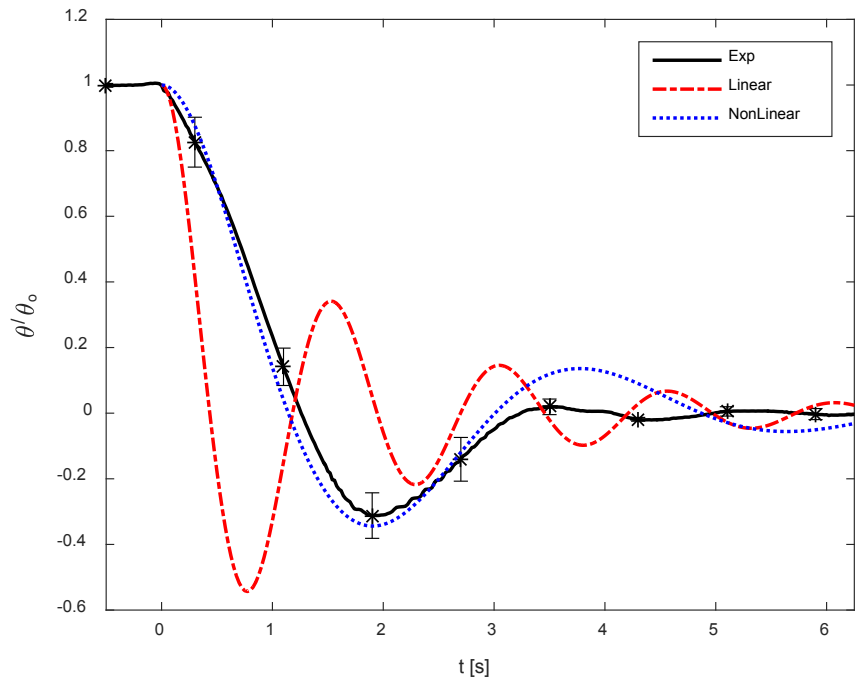

FIGURE 16. NORMALIZED FLAP PITCH DECAY FOR $10^{\circ}$ INITIAL DISPLACEMENT, EXPERIMENTAL RESULTS (SOLID), LINEAR WECSIM (DASHED), NONLINEAR WEC-SIM (DOTTED)

Experimental results from the flap pitch decay test are then compared to the WEC-Sim nonlinear simulations, shown in Figure 17. The experimental data is shown in a solid line with error bars denoting the $90 \%$ confidence interval. The results of the WEC-Sim flap pitch decay simulations for each initial displacement are shown as dotted lines. There is very good agreement between the experimental data and the corresponding WEC-Sim simulations. Both the experimental and numerical results exhibit natural periods and decay rates within reasonable error.

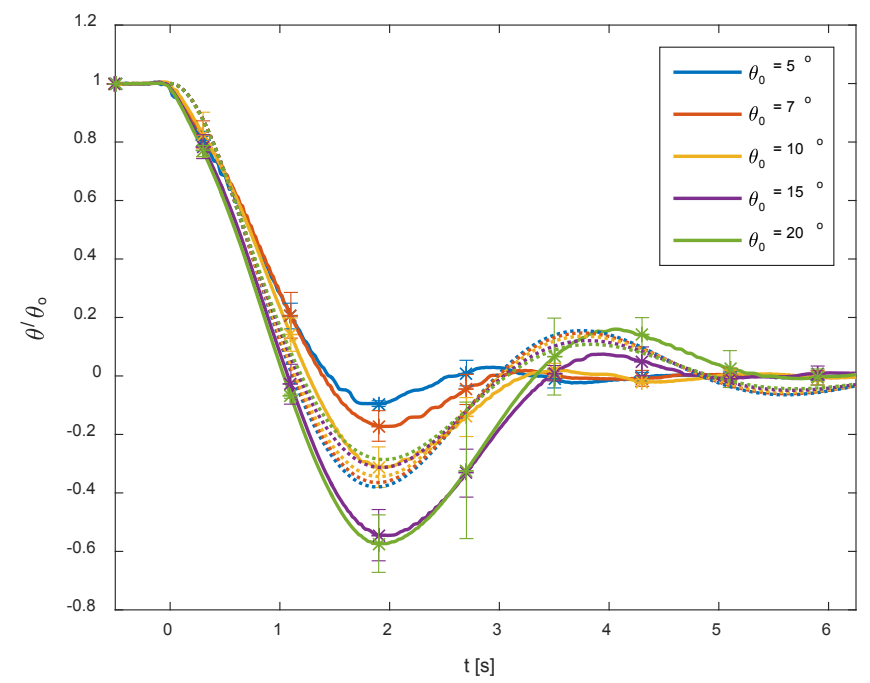

FIGURE 17. NORMALIZED FLAP PITCH DECAY EXPERIMENTAL RESULTS WITH 90\% CONFIDENCE INTERVAL (SOLID), AND WECSIM FLAP PITCH DECAY SIMULATIONS WITH NONLINEAR HYDROSTATICS, DAMPING OF 0 , AND C ${ }_{\mathrm{D}}$ OF 8 (DOTTED) 


\section{CONCLUSION}

This paper presents results from the Phase 1 WEC-Sim experimental testing of a prototype floating oscillating surge wave energy converter in comparison to numerical simulations using WEC-Sim. Phase 1 of physical wave basin testing was completed for a 1:33-scale model at Oregon State University in winter 2015, and Phase 2 is scheduled for spring 2016. The objective of this testing is to primarily to generate a comprehensive data set for validation of the WEC-Sim code, a secondarily to evaluate new instrumentation techniques for load characterization, and to provide a publicly available numerical benchmarking data set to be used by the wave energy community at large.

The paper presents results of using v2.0 of the WEC-Sim code to model FOSWEC Phase 1 experimental testing. Comparison of WEC-Sim simulations to experimental data serves as a preliminary effort towards WEC-Sim code validation. Phase 2 experimental testing will build upon the system identification experiments completed in Phase 1, and will be focused on characterization of the FOSWEC's response to various wave cases. Upon completion, the entire experimental data set - along with all numerical simulationswill be made publicly available and included in future releases of the WEC-Sim code.

\section{ACKNOWLEDGMENTS}

This research was possible through support from the Department of Energy's EERE Office's Wind and Water Power Technologies Office. The work was supported by Sandia National Laboratories, a multi-program laboratory managed and operated by Sandia Corporation, a wholly owned subsidiary of Lockheed Martin Corporation, for the U.S. Department of Energy's National Nuclear Security Administration under contract DE-AC04-94AL85000. This work was also supported by the U.S. Department of Energy under Contract No. DE-AC36-08GO28308 with the National Renewable Energy Laboratory.

This research was also supported in part by the Department of Energy's EERE Office's Wind and Water Power Technologies Office's Postdoctoral Research Awards administered by the Oak Ridge Institute for Science and Education (ORISE) for the DOE. ORISE is managed by Oak Ridge Associated Universities (ORAU) under DOE contract number DE-AC05-06OR23100.

The authors would also like to thank Christopher A. Kelley from Sandia National Laboratories, Pedro Lomonaco and Asher Simmons from Oregon State University, Andrews-Cooper for the design and fabrication of the FOSWEC, $+\mathrm{D}$ for design and fabrication of the motion constraint, and OSU HWRL staff for their part in supporting this research.

\section{REFERENCES}

[1] "MATLAB - The Language of Technical Computing." [Online]. Available: http://www.mathworks.com/products/matlab/.

[2] W. E. Cummins, "The impulse response function and ship motions," Schiffstechnik, vol. 9, pp. 101-109, 1962.

[3] K. Ruehl, C. Michelen, S. Kanner, M. Lawson, and Y. Yu, "Preliminary Verification and Validation of WEC-Sim, an Open-Source Wave Energy Converter Design Tool," in Proceedings of OMAE 2014, San Francisco, CA, 2014.

[4] M. Lawson, B. B. Garzon, F. Wendt, Y.-H. Yu, and C. Michelen, "COER Hydrodynamics Modeling Competition: Modeling the Dynamic Response of a Floating Body Using the WEC-SIM and FAST Simulation Tools," in Proceedings of OMAE 2015, St. John's, Newfoundland, Canada, 2015.

[5] Y. Yu, Ye Li, Kathleen Hallett, and Chad Hotimsky, "Design and Analysis for a Floating Oscillating Surge Wave Energy Converter," in Proceedings of OMAE 2014, San Francisco, CA, 2014.

[6] B. Bosma, K. Ruehl, A. Simmons, B. Gunawan, P. Lomonaco, and C. Kelley, "WEC-Sim Phase 1 Validation Testing - Experimental Setup and Initial Results (Article in Press)," in Proceedings of OMAE 2016, Busan, South Korea, 2016.

[7] "WEC-Sim GitHub Webpage." [Online]. Available: https://github.com/WEC-Sim/WEC-Sim.

[8] Kelley Ruehl, Carlos Michelen, Nathan Tom, Michael Lawson, Yi-Hsiang Yu, and Asher Simmons, "WEC-Sim Validation Testing Plan FY14 Q4," Sandia National Laboratories and National Renewable Energy Laboratory, SAND Report SAND2016-1339 R, Sep. 2014.

[9] "bemio GitHub Webpage." [Online]. Available: https://github.com/WEC-Sim/bemio.

[10] R. So, A. Simmons, T. Brekken, K. Ruehl, and C. Michelen, "Development of PTO-SIM: A Power Performance Module for the Open-Source Wave Energy Converter Code WEC-SIM," in Proceedings of OMAE 2015, St. John's, Newfoundland, Canada, 2015.

[11] "WEC-Sim Website." [Online]. Available: http://wecsim.github.io/WEC-Sim/.

[12] A. Babarit, J. Hals, A. Kurniawan, M. Muliawan, T. Moan, and J. Krokstad, "The NumWEC project: Numerical estimation of energy delivery from a selection of wave energy converters," 2011.

[13] MJ Lawson, Y. Yu, Adam Nelessen, Kelley Ruehl, and Carlos Michelen, "Implementing Nonlinear Buoyancy and Excitation Forces in the WEC-Sim Wave Energy Converter Modeling Tool," in Proceedings of OMAE 2014, San Francisco, CA, 2014.

[14] M. Lawson, Y.-H. Yu, A. Nelessen, K. Ruehl, and C. Michelen, "Implementing Nonlinear Buoyancy and Excitation Forces in the WEC-Sim Wave Energy Converter Modeling Tool," in Proceedings of the 33rd International Conference on Ocean, Offshore and Arctic Engineering (OMAE 2014), San Francisco, CA, 2014. 